Article

\title{
Recovery of Gallium from Simulated GaAs Waste Etching Solutions by Solvent Extraction
}

\author{
Wei-Sheng Chen ${ }^{1}$, Ko-Wei Tien ${ }^{1, *}$, Li-Pang Wang ${ }^{2, *}$, Cheng-Han Lee ${ }^{1} \mathbb{D}$ and Yi-Fan Chung ${ }^{1}$ \\ 1 Department of Resources Engineering, National Cheng Kung University, Tainan 701, Taiwan; \\ kenchen@mail.ncku.edu.tw (W.-S.C.); happy980074@gmail.com (C.-H.L.); eddie21039@gmail.com (Y.-F.C.) \\ 2 Institute of Environmental Engineering and Management, National Taipei University of Technology, \\ Taipei 106, Taiwan \\ * Correspondence: a6252626@gmail.com (K.-W.T.); kuniwang@ntut.edu.tw (L.-P.W.)
}

Received: 30 December 2019; Accepted: 25 February 2020; Published: 27 February 2020

\begin{abstract}
Gallium arsenide is used in semiconductor industries worldwide. Numerous waste etching solutions are produced during the processes of GaAs wafer production. Therefore, a complete and eco-friendly technology should be established to recover gallium as a gallium chloride solution and remove arsenic ion from waste GaAs etching solution. In this study, the gallium trichloride and arsenic trisulfide powders were dissolved in ammonia solutions to prepare the simulated solutions, and the $\mathrm{pH}$ value was adjusted to $\mathrm{pH} 2$ by nitric acid. In the extraction step, the GaAs etching solutions were extracted using $0.5 \mathrm{M}$ Cyanex 272 solutions in kerosene at $\mathrm{pH} 2$ and $0.1 \mathrm{O} / \mathrm{A}$ ratio for $5 \mathrm{~min}$. The extraction efficiency attained $77.4 \%$, which had an optimal ratio of concentration, and the four steps extraction efficiency attained $99.5 \%$. After extraction, iron sulfate heptahydrates were added into the raffinate, and the arsenic ions were precipitated. The removed rate attained $99.9 \%$ when the Fe/As ratio was 10. In the stripping step, the organic phase was stripped with $0.5 \mathrm{M}$ hydrochloric acid at 1 $\mathrm{O} / \mathrm{A}$ ratio for $3 \mathrm{~min}$, and $97.5 \%$ gallium was stripped. Finally, the purity of gallium chloride solution was $99.95 \%$ and the gallium was seven times the concentration of the etching solutions.
\end{abstract}

Keywords: gallium arsenide; Cyanex 272; bis(2,4,4-trimethylpentyl) phosphinic acid; arsenic precipitation

\section{Introduction}

Gallium is a valuable metal. It does not exist as a free element in nature but usually emerges as a trace element in sphalerite, germanite, bauxite, and zinc ores. World gallium production was 410 thousand kilograms in 2018 [1]. Various gallium compound materials are produced due to its great physical properties; these compounds include gallium nitride (GaN), indium gallium nitride (InGaN), gallium phosphide $(\mathrm{GaP})$, and gallium arsenide (GaAs).

Gallium arsenide is an important direct bandgap semiconductor material. GaAs has numerous advantages, including high saturated electron velocity and electron mobility, high thermal stability, wide operating temperature range, low noise in electronic circuits, and great resistance to radiation damage [2]. These advantages mean that GaAs has extensive applications in several industries, including for RF modules, power amplifier, substrate material, solar cells, infrared light-emitting diodes, radar system, space applications, and military applications [3]. According to the report of the US Geological Survey, the US imports of gallium mental were 23 thousand kilograms, and the imports of GaAs wafer were up to 630 thousand kilograms in 2018 [1]. The export and import of GaAs wafers were 60.58 tons and 73.32 tons in 2018 in Taiwan [4]. With the development of fifth generation cellular network technology, the demand for gallium arsenide will increase substantially. 
Gallium is usually produced as a byproduct of zinc refinery and Bayer liquor obtained during alumina production from bauxite [5]. However, the gallium ion concentration of bauxite varies from $33 \mathrm{ppm}$ to $86 \mathrm{ppm}$, which is much lower than the waste etching solutions. In the present, the gallium ion concentration of waste etching solutions was $244.9 \mathrm{ppm}$, which was three times to eight times the concentration of the bauxite [6]. Hence, it would be more efficient to recover gallium from waste etching solutions.

Multifarious extractants are presently used to recover gallium, including acidic extractant [7-9], basic extractant [10], neutral extractant [11-13], and chelation extractant [14]. Moreover, the alkyl phosphine compounds present an excellent extraction efficiency of gallium. For example, Ahmed et al. used Cyanex 923 (a mixture of four trialkyl phosphine oxides) and Cyanex 925 (bis (2,4,4-trimethylpentyl) octyl phosphine oxide) to recover gallium from a hydrochloric acid medium. Their result showed that Cyanex 925 is an outstanding extractant, but Cyanex 923 is commercially available and recommend [15]. Gupta et al. investigated Cyanex 923 and recovered $96 \%$ gallium with $0.2 \mathrm{M}$ Cyanex 923 from a gallium-indium binary system in $5 \mathrm{~min}$ [16]. Mishra et al. extracted gallium from aqueous chloride media with Cyanex 921 (tri-n-octyl phosphine oxide) in toluene in $\mathrm{pH} 4.5$. 99\% of gallium was recovered in $5 \mathrm{~min}$ [17]. Cyanex 301 (bis (2,4,4-trimethylpentyl) dithiophosphinic acid) was also used to extract gallium from Bayer's liquor, and up to $90 \%$ gallium was recovered [18]. Gupta et al. used $0.5 \mathrm{M}$ Cyanex 272 (bis (2,4,4-trimethylpentyl) phosphinic acid) to separate gallium ions and indium ions from the hydrochloric acid medium; it can recover $99 \%$ gallium in $5 \mathrm{~min}$ [19]. Zesen Zhao et al. also used Cyanex 272 to recover $81.7 \%$ of the gallium from the sulfuric acid leach liquor of coal fly ash at a pH of 2.4-2.6 [20]. Based on the previous researches, these alkyl phosphine compounds revealed the outstanding extraction efficiency to extract gallium. Moreover, Cyanex 272 has not been tested for the recovery of gallium from waste gallium arsenide etching solution, and the method of gallium recovery with Cyanex 272 could be suitable for arsenic precipitation. Considering the arsenic in the etching solution, R. J. Bowell mentioned that the arsenic could be precipitated when iron sulfate heptahydrates are added to the solution at a low $\mathrm{pH}$ value, high ORP value, and high temperature [21]. Wei-Ting Chen et al. also used ferrous sulfate heptahydrate to precipitate arsenic at a $\mathrm{pH}$ of 8 as ion arsenate, and the removal rate was $86 \%$ [22].

In this study, a novel way to recover gallium and remove arsenic from waste etching solution was investigated. The gallium ions and the arsenic ions in the simulated solutions were separated and the arsenic ions were removed from the raffinate. In the extraction step, Cyanex 272 was used to as the extractant, and kerosene was used as the diluent. The effect of $\mathrm{pH}$ value, extractant concentration, $\mathrm{O} / \mathrm{A}$ ratio (organic/aqueous ratio), extraction time, and multiple extraction steps were investigated, and the optimal ratio of concentration was chosen. After the extraction step, the $\mathrm{pH}$ value was suitable to precipitate arsenic with iron sulfate heptahydrate powders from the raffinate, and the $\mathrm{Fe} / \mathrm{As}$ ratio was determined. In the stripping step, the organic phase was stripped using hydrochloric acid. The effects of $\mathrm{O} / \mathrm{A}$ ratio, hydrochloric acid concentration, and extraction time were also investigated.

\section{Experimental}

\subsection{Materials}

The waste etching solutions were obtained from EPILEDS Co., Ltd. (Tainan, Taiwan). The etching solutions were ammonia solution and there were numerous precipitates in the solutions. Hence, the nitric acid was used to dissolve the precipitates and adjust the $\mathrm{pH}$ value of the waste etching solution to $\mathrm{pH} 2$ at the same time. Table 1 shows the concentration of waste etching solutions at $\mathrm{pH}$ 2. The extractant Cyanex 272 (bis(2,4,4-trimethylpentyl) phosphinic acid) supplied by Solvay Inc. (Longview, TX, USA) and used without any other purification. The diluent was kerosene purchased from the CPC Corporation (Kaohsiung, Taiwan). The gallium trichloride powders and arsenic trisulfide powders were supplied by Alfa Aesar (Haverhill, MA, USA), and the iron sulfate heptahydrate powders were supplied by Acros Organics (Morris Plains, NJ, USA). To prepare the simulated solution, 
the gallium trichloride and arsenic trisulfide powders were both dissolved in ammonia solutions and were adjusted to $\mathrm{pH} 2$ using nitric acid. The hydrochloric acid, nitric acid, and ammonia solutions were supplied from Sigma-Aldrich (Taufkirchen, Germany) and Honeywell Fluka (Shanghai, China).

Table 1. The ion concentration of waste etching solutions.

\begin{tabular}{cc}
\hline Element & Ion Concentration $(\mathbf{p p m})$ \\
\hline $\mathrm{Ga}$ & $244.9 \mathrm{ppm}$ \\
$\mathrm{As}$ & $108.5 \mathrm{ppm}$ \\
\hline
\end{tabular}

\subsection{Methods}

In this study, the simulated solutions were extracted with Cyanex 272 in kerosene and were shaken in $2500 \mathrm{rpm}$. The aqueous phases were collected after extraction, and the gallium and arsenic concentration of aqueous phases were analyzed by ICP-OES (Inductively Coupled Plasma-Optical Emission Spectrometry, Perkin Elmer optima 2100DV (PerkinElmer Inc. Waltham, MA, USA)). The ICP-OES was calibrated with an ICP multi-element standard solution. Each aqueous solution was analyzed for three-time and averaged for the reported data. To investigate the multiple extractions, the McCabe-Thiele diagram was constructed through six extractions in different gallium concentration and was compared to the actual value of multiple extraction. After the extraction step, the iron sulfate heptahydrate powders were added to the raffinate to precipitate arsenic ion. In the stripping step, the organic phases were stripped with hydrochloride acid and shaken in $2500 \mathrm{rpm}$. The gallium and arsenic concentration of hydrochloride acid were analyzed by ICP-OES.

\section{Results and Discussions}

\subsection{Cyanex 272 Extraction}

\subsubsection{Effect of $\mathrm{pH}$ Value}

The $\mathrm{pH}$ value was adjusted with nitric acid and ammonia solutions. The $\mathrm{pH}$ value was varied from $\mathrm{pH} 1$ to $\mathrm{pH} 3$ and $\mathrm{pH} 8$ to $\mathrm{pH} 11$ because gallium was precipitated at $\mathrm{pH} 4$ to $\mathrm{pH} 7$. According to Figure 1, the extraction efficiency increased at low $\mathrm{pH}$ value and sharply decreased at basic conditions due to the severe emulsification. The extraction efficiency was $99.8 \%$ at $\mathrm{pH} 2$. The result corresponded with other research that had an optimal extraction efficiency between $\mathrm{pH} 2$ and $\mathrm{pH} 3[19,20]$. Besides, $\mathrm{pH} 2$ was chosen as the optimal condition because the arsenic could be precipitated at $\mathrm{pH} 2$ after extraction. Compared with other studies, Gupta et al. revealed that the extraction efficiency attained $95 \%$ and $60 \%$ in $\mathrm{HCl}$ and $\mathrm{HNO}_{3}$ medium, respectively [19]. However, the extraction efficiency in this study also attained $99.8 \%$ when the solution contained nitric acid and chloride ions from gallium trichloride powders.

\subsubsection{Effect of Extraction Time}

The extraction time was controlled from $1 \mathrm{~min}$ to $60 \mathrm{~min}$. Figure 2 shows the efficiency in different extraction times. The extraction efficiency increased from $1 \mathrm{~min}$ to $5 \mathrm{~min}$ and attained maximum at $5 \mathrm{~min}$. The extraction efficiency decreased and attain equilibrium after $5 \mathrm{~min}$. The decrease was attributed to the change of $\mathrm{pH}$ value when the extraction equilibrated. According to Equation (1), Cyanex 272 released the $\mathrm{H}^{+}$during the extraction and changed the $\mathrm{pH}$ value [19].

$$
\mathrm{Ga}(\mathrm{OH})_{\mathrm{aq}}{ }^{2+}+\mathrm{H}_{2} \mathrm{R}_{2 \text { org }}<=>\mathrm{Ga}(\mathrm{OH}) \mathrm{R}_{2 \text { org }}+2 \mathrm{H}_{\mathrm{aq}}{ }^{+}
$$




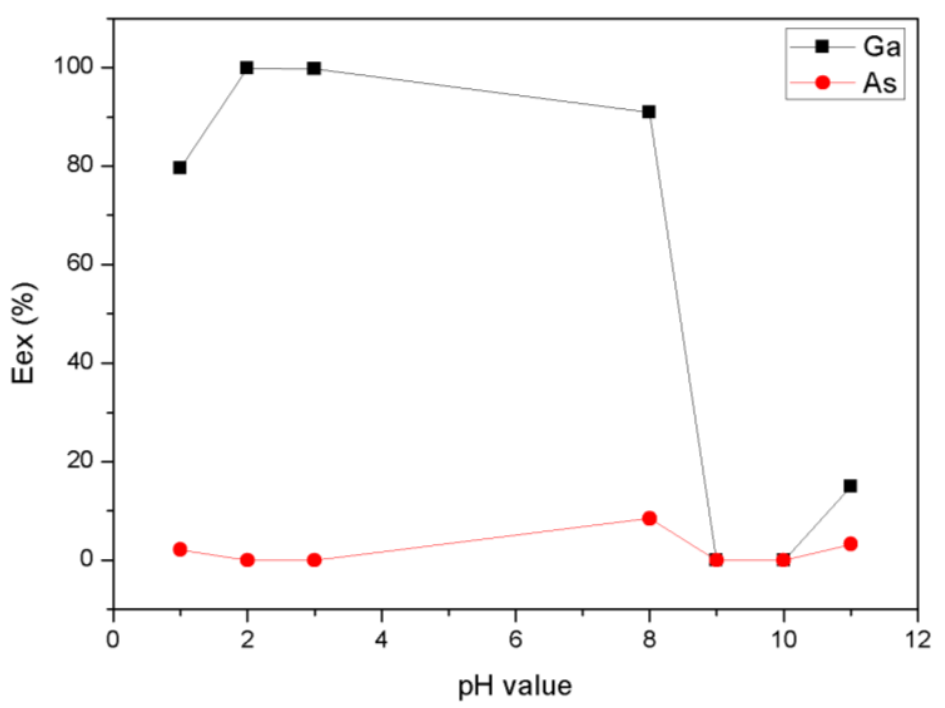

Figure 1. Plot of extraction $\mathrm{pH}$ value vs. extraction efficiency $\left(\mathrm{E}_{\mathrm{ex}} \%\right)$. [Ga concentration] $=250 \mathrm{ppm}$, $[$ As concentration $]=120 \mathrm{ppm},[$ Cyanex 272$]=0.1 \mathrm{M}, \mathrm{O} / \mathrm{A}$ ratio $=1$, time $=5 \mathrm{~min}$.

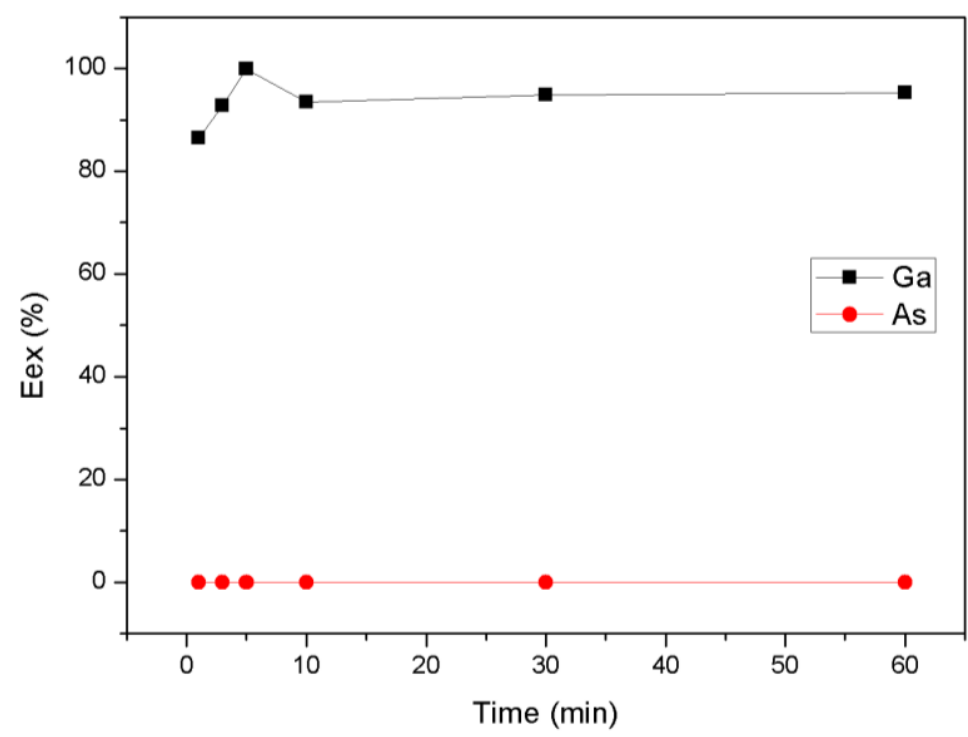

Figure 2. Plot of extraction time vs. extraction efficiency $\left(\mathrm{E}_{\mathrm{ex}} \%\right)$. [Ga concentration] $=250 \mathrm{ppm}$, [As concentration $]=120 \mathrm{ppm},[$ Cyanex 272$]=0.1 \mathrm{M}, \mathrm{pH}$ value $=2, \mathrm{O} / \mathrm{A}$ ratio $=1$.

The $\mathrm{pH}$ value dropped from 2 to 1.77 after $5 \mathrm{~min}$, and this was speculated the reason why the extraction efficiency decreased. Therefore, the optimal extraction time was $5 \mathrm{~min}$.

\subsubsection{Effect of Cyanex 272 Concentration}

The concentration of Cyanex varied from $0.001 \mathrm{M}$ to $0.5 \mathrm{M}$. Figure 3 reveals that the concentration of Cyanex 272 influenced the extraction efficiency. The extraction efficiency increased from $0 \%$ to $99.6 \%$ when the concentration of Cyanex increased from $0.001 \mathrm{M}$ to $0.5 \mathrm{M}$. The stoichiometry deficiency caused the poor extraction efficiency at $0.001 \mathrm{M}$. Hence, the optimal extractant concentration was $0.5 \mathrm{M}$. Compared with other research, the result also showed a similar positive correlation. 


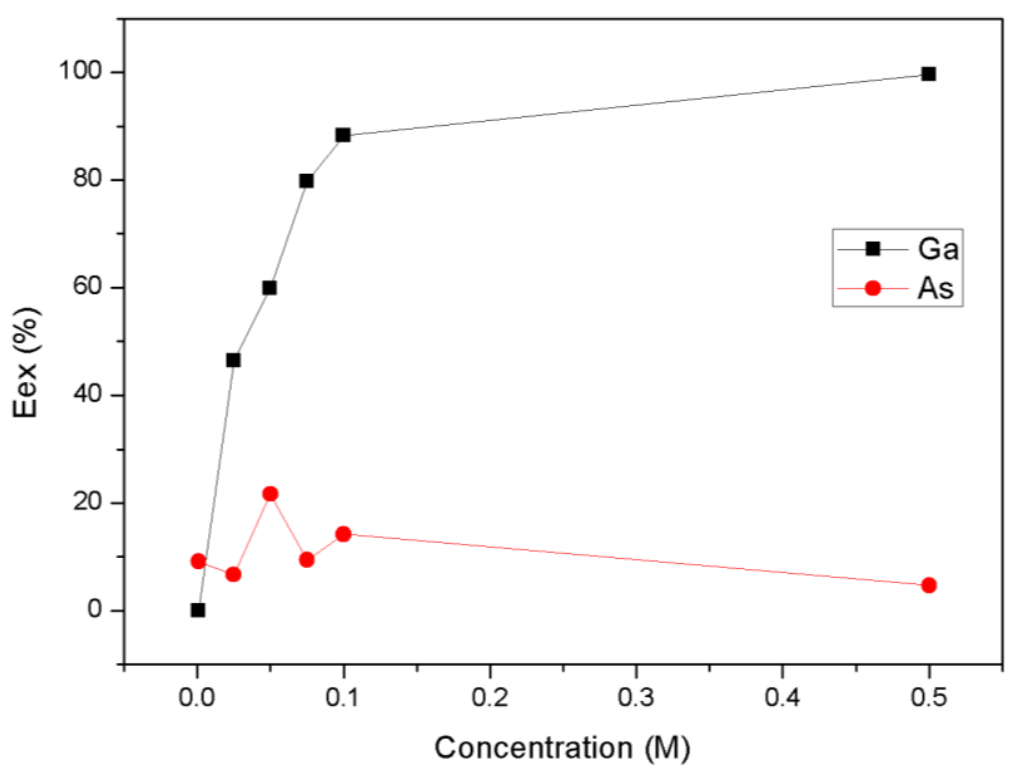

Figure 3. Plot of Cyanex 272 concentration vs. extraction efficiency $\left(\mathrm{E}_{\mathrm{ex}} \%\right)$. [Ga concentration] = $250 \mathrm{ppm}$, [As concentration] $=120 \mathrm{ppm}, \mathrm{pH}$ value $=2, \mathrm{O} / \mathrm{A}$ ratio $=1$, time $=5 \mathrm{~min}$.

\subsubsection{Effect of Extraction O/A Ratio}

The $\mathrm{O} / \mathrm{A}$ ratio was investigated and was set from 0.05 to 2 . Figure 4 shows the extraction efficiency, which increased from $47.073 \%$ to $99.9 \%$. The most effective O/A ratio was 2 . However, the optimal parameter was chosen at $\mathrm{O} / \mathrm{A}$ ratio of 0.1 due to its outstanding ratio of concentration. The gallium concentration of organic phase increased from $124.8 \mathrm{ppm}$ to $1935.6 \mathrm{ppm}$ when the O/A ratio changed from 2 to 0.1 . Despite the efficiency was lower than O/A ratio 2, this problem could be solved with multiple extractions. Table 2 showed the ratio of concentration varied with O/A ratio. Although the extraction efficiency was lower than other studies with an O/A ratio of 0.1 , the effect of concentration was excellence and the gallium concentration of organic phase attained $1935.6 \mathrm{ppm}$.

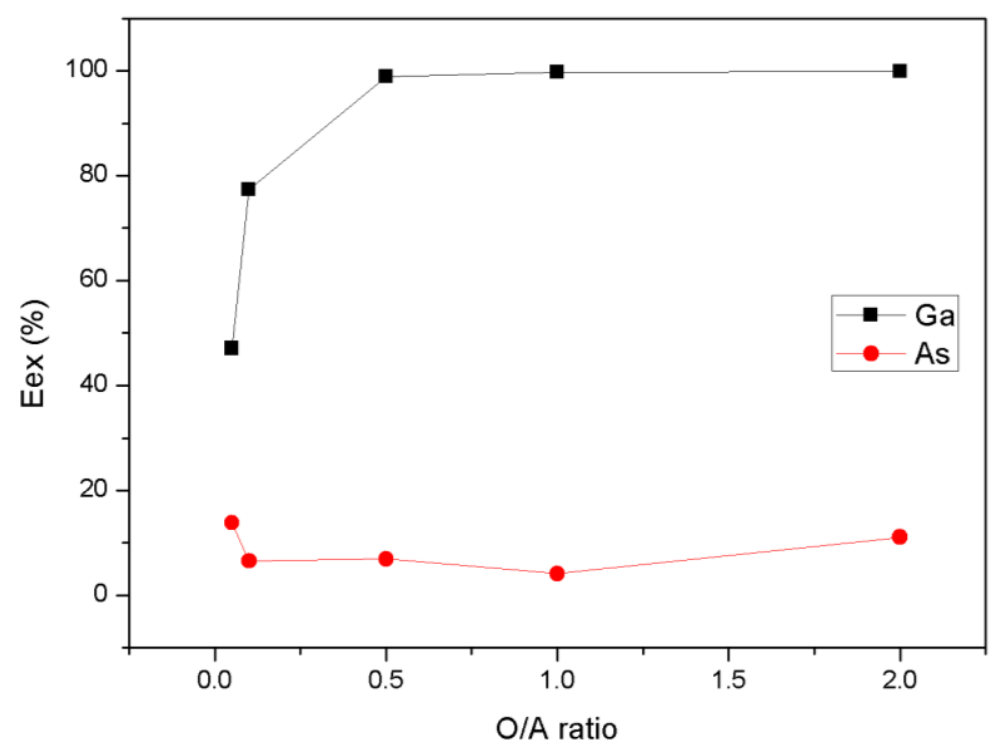

Figure 4. Plot of O/A ratio vs. extraction efficiency $\left(\mathrm{E}_{\mathrm{ex}} \%\right)$. [Ga concentration] $=250 \mathrm{ppm}$, $[$ As concentration $]=120 \mathrm{ppm},[$ Cyanex 272$]=0.5 \mathrm{M}, \mathrm{pH}$ value $=2$, time $=5 \mathrm{~min}$. 
Table 2. The $\mathrm{E}_{\mathrm{ex}}(\%)$ and the ratio of concentration compared with $\mathrm{O} / \mathrm{A}$ ratio.

\begin{tabular}{ccc}
\hline O/A Ratio & $\mathbf{E}_{\mathbf{e x}} \mathbf{( \% )}$ & Ratio of Concentration (\%) \\
\hline \multirow{2}{*}{2} & Ga: $99.9 \%$ & Ga: $49.9 \%$ \\
& As: $11.1 \%$ & As: $5.6 \%$ \\
\hline \multirow{2}{*}{1} & Ga: $99.7 \%$ & Ga: $99.7 \%$ \\
& As: $4.1 \%$ & As: $4.1 \%$ \\
\hline \multirow{2}{*}{0.5} & Ga: $98.9 \%$ & Ga: $197.8 \%$ \\
& As: $6.9 \%$ & As: $13.8 \%$ \\
\hline \multirow{2}{*}{0.1} & Ga: $77.4 \%$ & Ga: $774.2 \%$ \\
& As: $6.6 \%$ & As: $65.6 \%$ \\
\hline \multirow{2}{*}{0.05} & Ga: $47.1 \%$ & Ga: $1225.9 \%$ \\
& As: $13.8 \%$ & As: $276.5 \%$ \\
\hline
\end{tabular}

\subsubsection{Extraction Efficiency of Multiple Extractions}

Although the $\mathrm{O} / \mathrm{A}$ ratio resulted in lower extraction efficiency, multiple extractions can solve this problem. The multiple extractions corroborated that the extraction efficiency attained $97.9 \%$ in three steps and $99.5 \%$ in four steps, respectively.

The McCabe-Thiele diagram and the theoretical extraction step are depicted in Figure 5. The McCabe-Thiele diagram show that the extraction steps were four steps and the extraction efficiency attained $99.9 \%$ in $0.1 \mathrm{O} / \mathrm{A}$ ratio. Hence, the experimental result was confirmed.

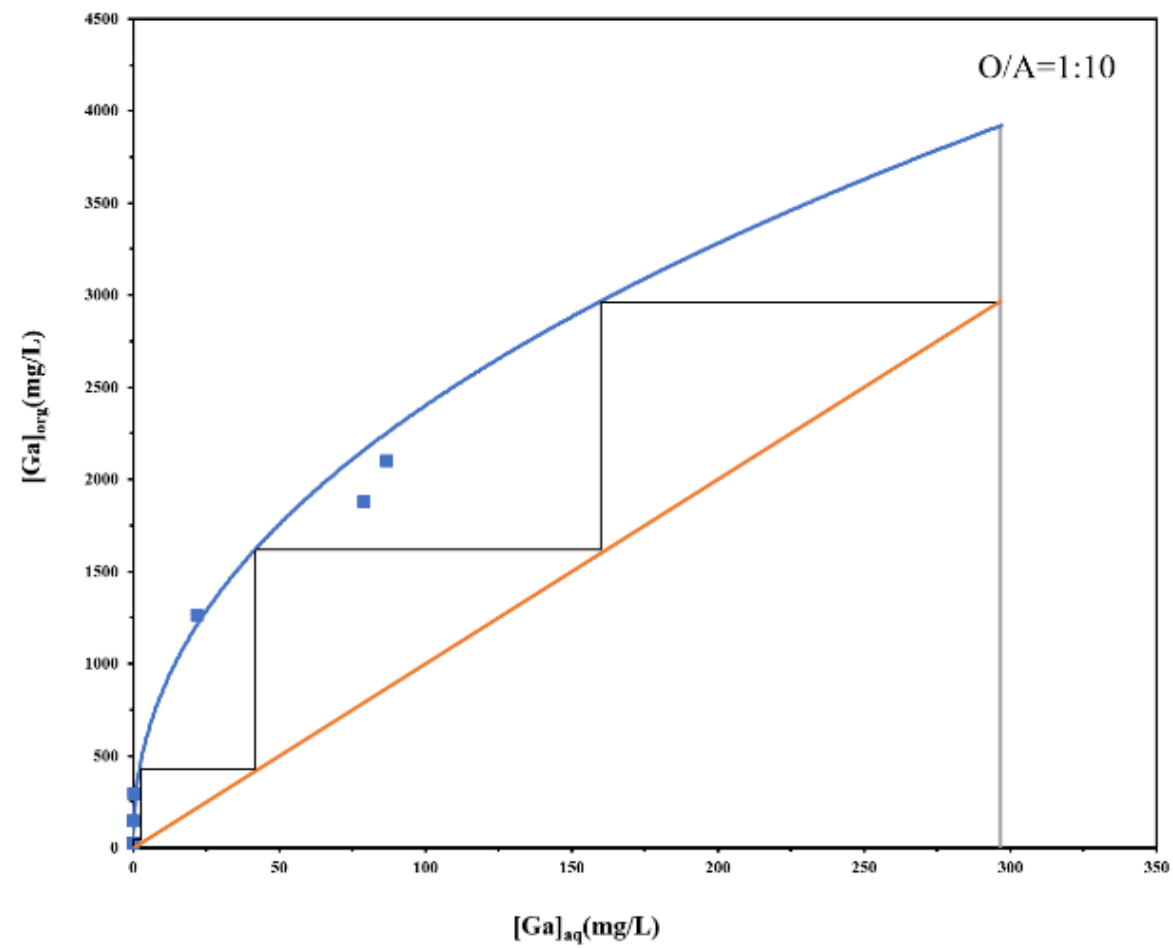

Figure 5. The McCabe-Thiele diagram.

\subsubsection{Arsenic Removed}

According to the research of R. J. Bowell, arsenic precipitated when ferrous sulfate was added to the low $\mathrm{pH}$ value, high redox potential, and high temperature arsenic solution [21]. The $\mathrm{pH}$ value of raffinate was in the range of arsenic precipitation and the ORP value was adjusted to $437 \mathrm{mV}$. The iron sulfate heptahydrate powders were added, and the Fe/As ratio was investigated from 1 to 10 . 
Figure 6 showed that $99.9 \%$ arsenic was removed when the Fe/As ratio was 10. In order to remove the arsenic completely, a $10 \mathrm{Fe} / \mathrm{As}$ ratio was chosen. The result also corresponded with the research of R. J. Bowell, which means this method has the potential to be used in GaAs waste etching solution treatment. Compared with other studies, the arsenic ion would be useful to precipitate at a low $\mathrm{pH}$ value rather than under neutral conditions because of the excellent removed rate [22].

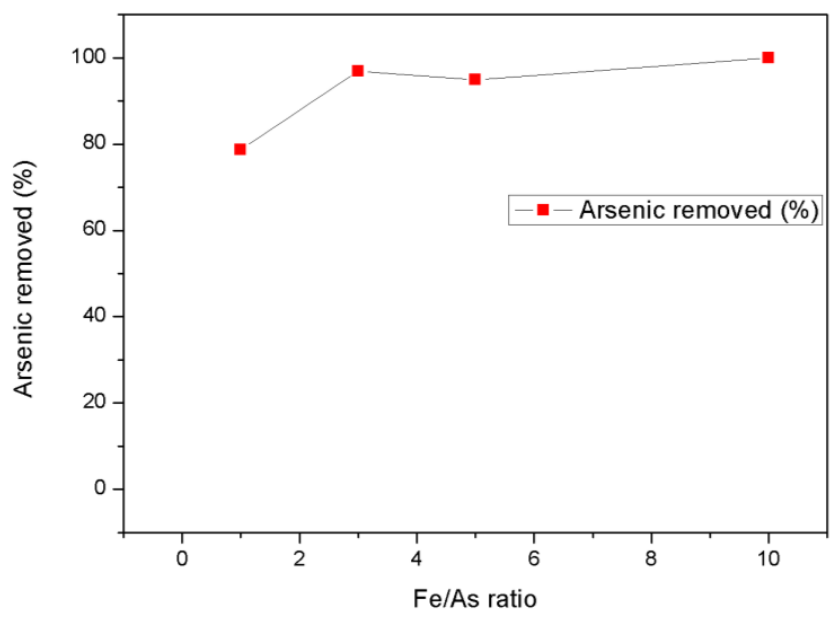

Figure 6. Plot of $\mathrm{Fe} / \mathrm{As}$ ratio vs. arsenic removed rate. [As concentration] $=110 \mathrm{ppm}$, $\mathrm{pH}$ value $=2$, ORP value $=437 \mathrm{mV}$, temperature $=95^{\circ} \mathrm{C}$, time $=1 \mathrm{~h}$.

\subsection{Hydrochloric Acid Stripping}

\subsubsection{Effect of Hydrochloric Acid Concentration}

After extraction, the $\mathrm{pH}$ value of organic phase was 2.87. According to the research of Gupta et al., hydrochloric acid showed a better stripping efficiency than nitric acid and sulfuric acid [19]. To recover high purity gallium chloride solution and investigate the effect between hydrochloric acid and stripping efficiency, the hydrochloric acid concentration was studied in $0.1 \mathrm{M}, 0.5 \mathrm{M}, 1 \mathrm{M}, 2 \mathrm{M}$. Figure 7 showed that the stripping efficiency increased with the hydrochloric acid concentration. Through the cation exchanged, $99.9 \%$ gallium was stripped from the organic phase at $0.5 \mathrm{M}$. Compared with the result of extraction, although part of arsenic extracted to the organic phase, the gallium could be separated from the arsenic completely in the stripping step.

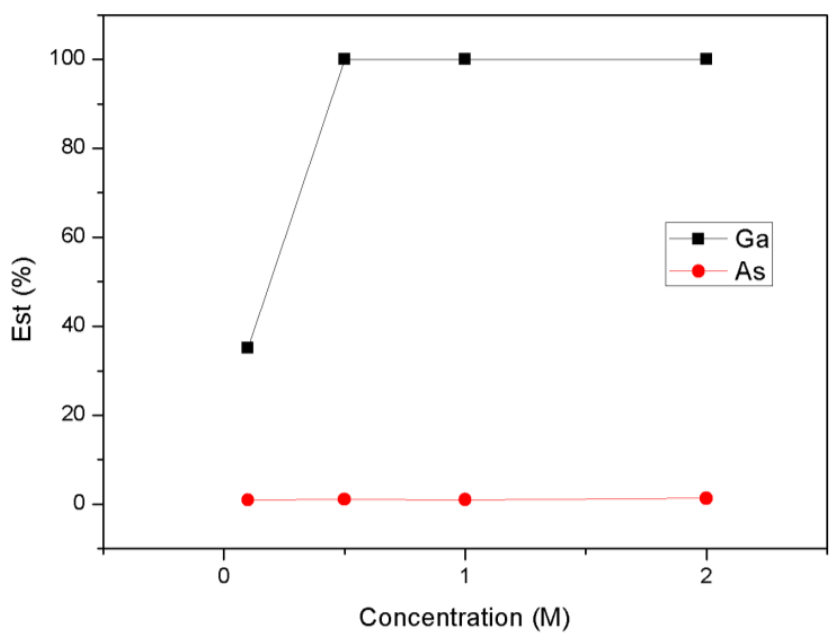

Figure 7. Plot of hydrochloric acid concentration vs. stripping efficiency $\left(\mathrm{E}_{\mathrm{st}} \%\right)$. [Ga concentration] $=$ $1300 \mathrm{ppm},[$ As concentration $]=60 \mathrm{ppm}, \mathrm{O} / \mathrm{A}$ ratio $=1$, time $=5 \mathrm{~min}$. 


\subsubsection{Effect of Stripping O/A Ratio}

To confirm the maximum gallium concentration in hydrochloric acid, the stripping $\mathrm{O} / \mathrm{A}$ ratio was investigated. Figure 8 shows the result of stripping O/A ratio. The O/A ratio varied from 10 to 0.1 , and the stripping was increased from $67.4 \%$ to $98.1 \%$. When the $\mathrm{O} / \mathrm{A}$ ratio was higher than 1 , the stripping efficiency decreased violently due to the overload. Hence, the optimal O/A ratio was 1 to strip the gallium.

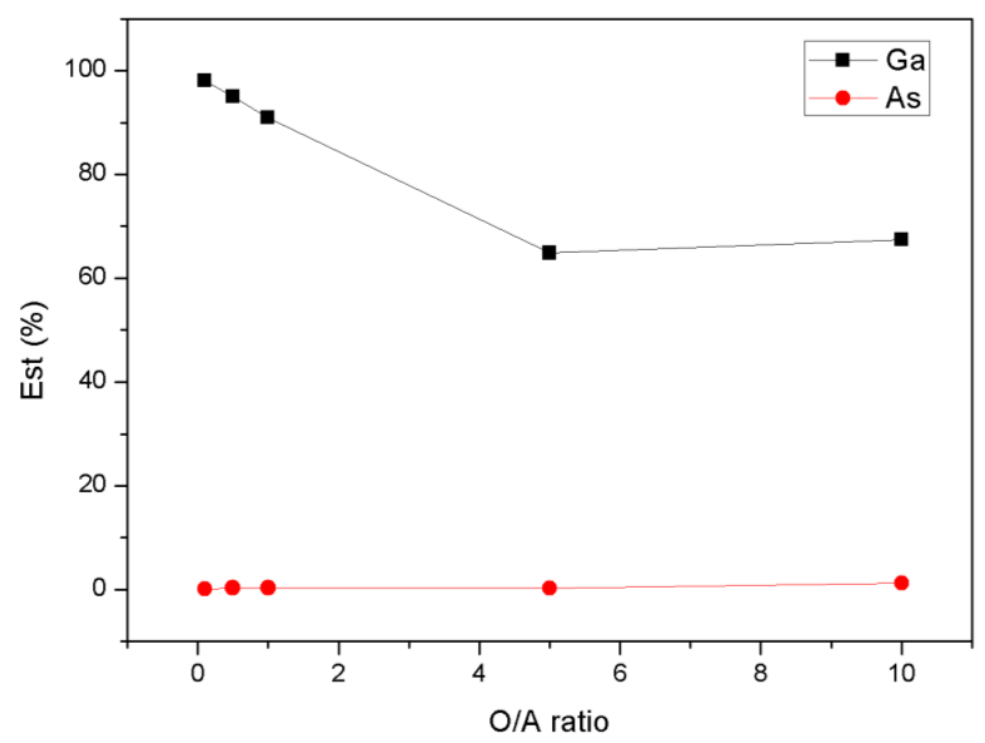

Figure 8. Plot of $\mathrm{O} / \mathrm{A}$ ratio vs. stripping efficiency $\left(\mathrm{E}_{\mathrm{st}} \%\right)$. [Ga concentration] $=1300 \mathrm{ppm}$, $[$ As concentration $]=60 \mathrm{ppm},[\mathrm{HCl}$ concentration $]=0.5 \mathrm{M}$, time $=5 \mathrm{~min}$.

\subsubsection{Effect of Stripping Time}

The stripping time was studied from $1 \mathrm{~min}$ to $60 \mathrm{~min}$. Figure 9 showed that the stripping attained equilibrium in $3 \mathrm{~min}$ and maintained high stripping efficiency. Hence, the optimal stripping time was $3 \mathrm{~min}$.

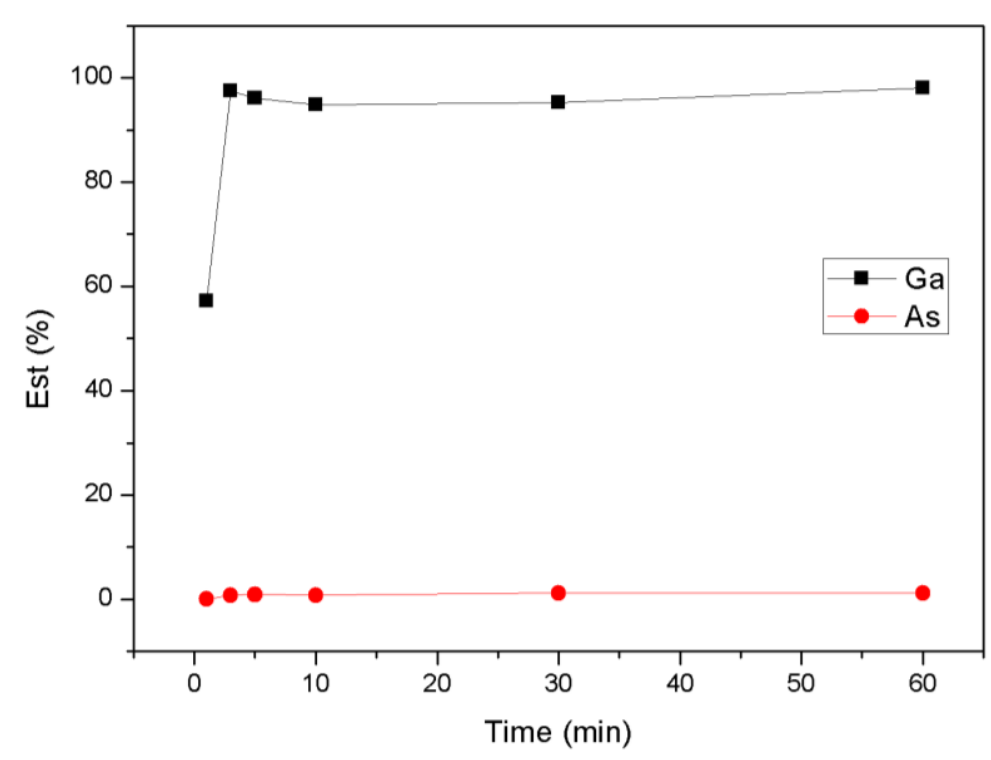

Figure 9. Plot of stripping time vs. stripping efficiency $\left(\mathrm{E}_{\mathrm{st}} \%\right)$. [Ga concentration] $=1300 \mathrm{ppm}$, $[$ As concentration $]=60 \mathrm{ppm},[\mathrm{HCl}$ concentration $]=0.5 \mathrm{M}, \mathrm{O} / \mathrm{A}$ ratio $=1$. 


\section{Conclusions}

We confirmed an efficient technology to recover high purity gallium chloride solution with Cyanex 272 and to remove arsenic in the raffinate. The optimal extraction parameters were $\mathrm{pH} 2,0.5 \mathrm{M}$ Cyanex $272,0.1 \mathrm{O} / \mathrm{A}$ ratio, and an extraction time of $5 \mathrm{~min}$, and the extraction attained $77.4 \%$. The $\mathrm{pH}$ value of 2 was chosen because of the optimal extraction efficiency and the range of arsenic precipitation. In order to promote the ratio of concentration, the extraction efficiency was not very outstanding. However, this problem could be solved through multiple extractions to heave the extraction efficiency until $99.5 \%$. After extraction, iron sulfate heptahydrate powders were added into the raffinate at $\mathrm{pH}=2$, ORP value $=437 \mathrm{mV}, 95^{\circ} \mathrm{C}$, for one hour. The arsenic removal rate attained $99.9 \%$ when the $\mathrm{Fe} / \mathrm{As}$ ratio was 10 . To recover high purity gallium chloride solution, hydrochloride acid was chosen as the stripping agent. The optimal stripping parameter was $0.5 \mathrm{M}$ hydrochloric acid, $1 \mathrm{O} / \mathrm{A}$ ratio, and a time of $3 \mathrm{~min}$. The stripping efficiency attained $97.5 \%$. In conclusion, the $99.95 \%$ purity gallium chloride solution was recovered, and $99.9 \%$ arsenic was removed from the raffinate. To fulfill the circular economy, the high purity gallium chloride solution will be used to produce GZO film in an eco-friendly way in the future.

Author Contributions: Conceptualization, W.-S.C., K.-W.T. and L.-P.W.; Methodology, K.-W.T., C.-H.L. and Y.-F.C.; Data Curation, K.-W.T.; Writing-Original Draft Preparation, K.-W.T.; Writing-Review \& Editing, K.-W.T. All authors have read and agreed to the published version of the manuscript.

Funding: This research received no external funding.

Conflicts of Interest: The authors declare no conflict of interest.

\section{References}

1. U.S. Geological Survey. Mineral Commodity Summaries 2019; U.S. Geological Survey: Reston, VA, USA, 2019; pp. 62-63.

2. Chen, W.T.; Tsai, L.C.; Tsai, F.C.; Shu, C.M. Recovery of Gallium and Arsenic from Gallium Arsenide Waste in the Electronics Industry. Clean Soil Air Water 2012, 40, 531-537. [CrossRef]

3. Moskalyk, R.R. Gallium: The Backbone of the Electronics Industry. Miner. Eng. 2003, 16, 921-929. [CrossRef]

4. Customs Administration, Trade Statistics Search. Available online: https://portal.sw.nat.gov.tw/APGA/GA03E (accessed on 31 July 2019).

5. Zhao, Z.; Yang, Y.; Xiao, Y.; Fan, Y. Recovery of gallium from Bayer liquor: A review. Hydrometallurgy 2012, 125, 115-124. [CrossRef]

6. Schulz, K.J.; DeYoung, J.H., Jr.; Seal, R.R.I.I.; Bradley, D.C. Critical mineral resources of the United States-Economic and environmental geology and prospects for future supply. Geol. Surv. Prof. Pap. 2017, 1802, H1-H35.

7. Lee, M.; Ahn, J.; Lee, E. Solvent extraction separation of indium and gallium from sulphate solutions using D2EHPA. Hydrometallurgy 2002, 63, 269-276. [CrossRef]

8. Nusen, S.; Chairuangsri, T.; Zhu, Z.; Cheng, C. Recovery of indium and gallium from synthetic leach solution of zinc refinery residues using synergistic solvent extraction with LIX 63 and Versatic 10 acid. Hydrometallurgy 2016, 160, 137-146. [CrossRef]

9. Bhattacharya, B.; Mandal, D.; Mukherjee, S. Liquid-Liquid Extraction of Gallium(III) with LIX 26. Sep. Sci. Technol. 2003, 38, 1417-1427. [CrossRef]

10. Fan, S.; Jia, Q.; Song, N.; Su, R.; Liao, W. Synergistic extraction study of indium from chloride medium by mixtures of sec-nonylphenoxy acetic acid and trialkyl amine. Sep. Purif. Technol. 2010, 75, 76-80. [CrossRef]

11. Pawar, S.; Dhadke, P. Extraction and separation studies of $\mathrm{Ga}(\mathrm{III}), \mathrm{In}(\mathrm{III})$ and $\mathrm{Tl}(\mathrm{III})$ using the neutral organophosphorous extractant, Cyanex-923. J. Serb. Chem. Soc. 2003, 68, 581-591. [CrossRef]

12. Iyer, J.; Dhadke, P. Liquid-liquid extraction and separation of gallium (III), indium (III), and thallium (III) by Cyanex-925. Sep. Sci. Technol. 2001, 36, 2773-2784. [CrossRef]

13. Macías-Macías, K.Y.; Ceniceros-Gómez, A.E.; Gutiérrez-Ruiz, M.E.; González-Chávez, J.L.; Martínez-Jardines, L.G. Extraction and recovery of the strategic element gallium from an iron mine tailing. J. Environ. Chem. Eng. 2019, 7, 102964. [CrossRef] 
14. Kekesi, T. Gallium extraction from synthetic Bayer liquors using Kelex 100-kerosene, the effect of loading and stripping conditions on selectivity. Hydrometallurgy 2007, 88, 170-179. [CrossRef]

15. Ahmed, I.M.; El-Nadi, Y.A.; El-Hefny, N.E. Extraction of gallium (III) from hydrochloric acid by Cyanex 923 and Cyanex 925. Hydrometallurgy 2012, 131, 24-28. [CrossRef]

16. Gupta, B.; Deep, A.; Malik, P. Liquid-liquid extraction and recovery of indium using Cyanex 923. Anal. Chim. Acta 2004, 513, 463-471. [CrossRef]

17. Mishra, B.T.; Rokade, M.D.; Dhadke, P.M. Liquid-Liquid extraction and separation of gallium (III) with Cyanex 921. Indian J. Chem. 2000, 39, 1114-1116.

18. Gupta, B.; Mudhar, N.; Tandon, S.N. Extraction and Separation of Gallium Using Cyanex 301: Its Recovery from Bayer's Liquor. Ind. Eng. Chem. Res. 2005, 2005, 1922-1927. [CrossRef]

19. Gupta, B.; Mudhar, N.; Singh, I. Separations and recovery of indium and gallium using bis (2,4, 4-Trimethylpentyl) phosphinic acid (Cyanex 272). Sep. Purif. Technol. 2007, 57, 294-303. [CrossRef]

20. Zhao, Z.; Cui, L.; Guo, Y.; Li, H.; Cheng, F. Recovery of gallium from sulfuric acid leach liquor of coal fly ash by stepwise separation using P507 and Cyanex 272. Chem. Eng. J. 2020, 381, 122699. [CrossRef]

21. Bowell, R.J. Assessment of Scorodite Precipitation from Mine Waters. Mine Water Risk Oppor. 2018, 1, 91-97.

22. Chen, W.; Chu, Y.; Wei, J.; Tsai, L.; Tsai, F.; Lin, C.; Shu, C. Gallium and Arsenic Recovery from Waste Gallium Arsenide by Wet Refined Methods. Adv. Mater. Res. 2011, 194, 2115-2118. [CrossRef]

(C) 2020 by the authors. Licensee MDPI, Basel, Switzerland. This article is an open access article distributed under the terms and conditions of the Creative Commons Attribution (CC BY) license (http://creativecommons.org/licenses/by/4.0/). 